\title{
Myelopathic signs and functional outcome following cervical decompression surgery: a proposed myelopathy scale
}

\author{
Salem El-Zuway, MD, FRCSC,1,3 Forough Farrokhyar, BSc, MPhil, PhD, ${ }^{2}$ and \\ Edward Kachur, MD, FRCSC1,3 \\ ${ }^{1}$ Division of Neurosurgery, Department of Surgery, ${ }^{2}$ Department of Clinical Epidemiology \& Biostatistics, Faculty of Health \\ Sciences, McMaster University; and ${ }^{3}$ Hamilton Health Sciences, Hamilton, Ontario, Canada
}

\begin{abstract}
OBJECTIVE Cervical spondylotic myelopathy (CSM) is the most common cause of spinal cord dysfunction in adults. In spite of this, the impact of the changes in myelopathic signs following cervical decompression surgery and their relationship to functional outcome measures remains unclear. The main goals of our study were to prospectively assess changes in myelopathic signs with a functional outcome scale (the modified Japanese Orthopaedic Association [mJOA] scale) following cervical decompression surgery and to objectively test a proposed new myelopathy scale (MS).

METHODS Between 2008 and 2011, 36 patients with CSM were observed following cervical decompression surgery. Patient data including mJOA and MS scores were prospectively collected and analyzed preoperatively and at 1 year after surgery.

RESULTS In this cohort, reflex, Babinski, and proprioception signs showed statistically significant improvement following surgery at 1 year $(p=<0.001, p=0.008$, and $p=0.015$, respectively). A lesser degree of improvement was observed with the Hoffman sign $(p=0.091)$. No statistically significant improvement in clonus occurred $(p=0.368)$. There was a significant improvement in mJOA ( $p \leq 0.001)$ and MS $(p \leq 0.001)$ scores at 1 year compared with the preoperative scores. The results showed an inverse correlation between MS and mJOA scores both pre- and postoperatively (Spearman's correlation coefficient $=-0.202$ preoperatively and -0.361 postoperatively).
\end{abstract}

CONCLUSIONS Improvement in myelopathic signs was noted following cervical decompression surgery in patients with CSM. The newly devised MS scale demonstrated these findings, and the new MS scale correlates with improvement in mJOA scores in this patient cohort.

http://thejns.org/doi/abs/10.3171/2015.9.SPINE139

KEY WORDS cervical spondylosis; functional outcome; myelopathy; scale; cervical decompression surgery

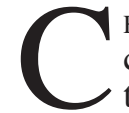
ERVICAL spondylotic myelopathy (CSM) is a clinicoradiological entity resulting from narrowing of the cervical spinal canal from degenerative changes with subsequent compression of the cervical cord. It is by far the most common cause of myelopathy in the cervical spine..$^{1,3,4}$ It is characterized by a series of complex long-tract signs and symptoms. CSM may present with an indolent course or may follow a more detrimental progressive course. ${ }^{9,14}$ In spite of the fact that CSM is the most common cause of myelopathy of the cervical spine, there is a paucity of information in the literature regarding changes in myelopathic signs following cervical decompression surgery and the comparison of the impact of these changes in a patient's myelopathic signs to actual changes in functional outcome. Although a variety of functional outcome instruments have been used for assessing patients with CSM, to our knowledge there is no known objective myelopathic scale that evaluates patients with CSM based solely on myelopathic signs. ${ }^{6}$ Numerous scales to assess myelopathy have been suggested in the literature. ${ }^{2,5,7,8,12,13}$ The Myelopathy Disability Index, modified Japanese Orthopaedic Association (mJOA) scale, Prolo-score scale, Cooper scale, and others have all been used. The common theme shared by these scales is the degree of subjectivity inherent in each scale and the lack of use of myelopathic signs.

ABBREVIATIONS CSM = cervical spondylotic myelopathy; mJOA = modified Japanese Orthopaedic Association; MS = myelopathy scale .

SUBMITTED January 4, 2013. ACCEPTED September 28, 2015.

INCLUDE WHEN CITING Published online February 5, 2016; DOI: 10.3171/2015.9.SPINE139. 
Some researchers have recommend the use of functional (subjective) outcome scales in the assessment of patients undergoing surgery for CSM, because such scales have proven to be valid and reliable. ${ }^{6,16}$ The need to have a more definitive objective assessment tool that would further aid in the surgical decision-making process for cervical myelopathy has led us to the creation of the myelopathy scale (MS; Fig. 1). When we designed this scale, we took into consideration 3 fundamental prerequisites: user-friendliness, simplicity, and comprehensibility. Hence, the main objective of the current study was to observe changes in myelopathic signs on an individual basis and as part of this newly devised scale. These changes were compared with a widely accepted functional outcome scale, the modified Japanese Orthopaedic Association (mJOA) scale, which assesses motor and gait function for patients with CSM (Table 1).

\section{Methods \\ Demographic Data}

Inclusion criteria for the study were adult patients 18 years and older, with CSM secondary to degenerative etiologies, who underwent cervical decompression surgery performed by the authors (S.E. and E.K.). Exclusion criteria were patients with isolated cervical radiculopathy, concurrent neurological conditions (i.e., stroke/cerebrovascular accidents, spinal epidural lesions [tumor, abscess, or hematoma], spinal tumor [primary or secondary], brain tumor, multiple sclerosis, normal pressure hydrocephalus, syringomyelia, and peripheral neuropathy), prior cervical spine surgery, cervical deformity, and trauma patients. Thus, the prospective cohort included patients with CSM who underwent cervical decompressive surgery at Hamilton General Hospital, McMaster University, over a 3-year period from June 2008 to May 2011. Assessments both preoperatively and 1-year postoperatively were performed by the authors (S.E. and E.K.).

\section{Surgical Treatment}

A full range of surgical options both anteriorly and posteriorly were used. The choice and the recommendation of the approach were based on the severity of the pathology and the number of levels involved, at the discretion of the authors (S.E. and E.K.). Anterior approaches (corpectomy, single- or multilevel anterior cervical discectomy), posterior approaches (laminectomy, laminectomy with instrumentation-fusion, and expansive laminoplasty) and combined approaches were used. In this study, expansive cervical laminoplasty was the most frequently used technique (30 patients, $83.3 \%$ ).

\section{Clinical Evaluation}

Eligible patients were assessed prospectively by the authors independently at the Neurosurgery Spine Clinic at Hamilton General Hospital, McMaster University, over a 3 -year period. To assess the severity of myelopathy, our newly proposed MS and the mJOA scale were used. The maximum score for the mJOA scale is 17 . The MS is a 10 -point score scale $(0-10)$ based on 5 fundamental signs

\section{The Myelopathy Scale}
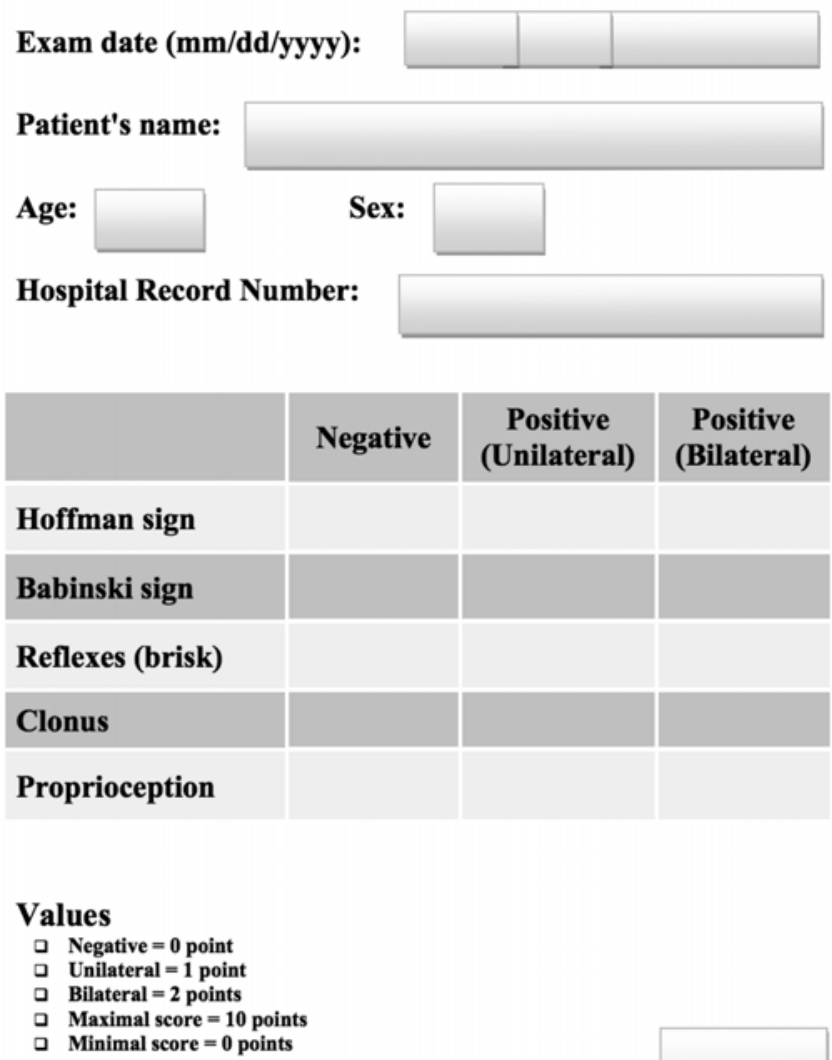

Total score:

FIG. 1. Proposed MS. This scale is based on 5 basic myelopathic signs (Hoffman, Babinski, reflexes, proprioception, and clonus): a score of 0 if the sign is absent, 1 if unilateral, and 2 if bilateral. The maximum score is 10 and minimum is 0.

of myelopathy (Hoffman sign, Babinski sign, reflexes, proprioception, and clonus). A score of zero was given if the sign is absent, 1 if unilateral, and 2 if bilateral. The higher the scoring grade, the worse the degree of myelopathy. Reflexes were judged to be brisk and abnormal if they were graded $\geq 3$ on a scale from 0 to 4 .

The clinical diagnosis and the decision for surgical intervention were based on clinical assessment and radiological evidence using MRI at the discretion of the authors. Myelopathy was assessed preoperatively and 1-year postoperatively. Both scales were used to assess the degree of clinical and symptomatic improvement postoperatively, and both scales were compared with each other.

\section{Statistical Analysis}

Descriptive statistics were collected. Categorical variables were reported as frequencies, relative frequencies, and continuous variable means with standard deviations, or medians with minimums and maximums if not normally distributed. Categorical variables were compared using 
TABLE 1. Modified JOA scale by Keller et al., 1993

\begin{tabular}{|c|c|c|}
\hline Criterion & Clinical Situation & Points* \\
\hline \multirow{5}{*}{$\begin{array}{l}\text { Motor function upper } \\
\text { extremity }\end{array}$} & Paralysis & 1 \\
\hline & $\begin{array}{l}\text { Fine motor function massively } \\
\text { decreased }\end{array}$ & 2 \\
\hline & Fine motor function decelerated & 3 \\
\hline & $\begin{array}{l}\text { Discreet weakness in hands or proxi- } \\
\text { mal arm }\end{array}$ & 4 \\
\hline & Normal function & 5 \\
\hline \multirow{5}{*}{$\begin{array}{l}\text { Motor function lower } \\
\text { extremity }\end{array}$} & Unable to walk & 1 \\
\hline & Need walking aid on flat floor & 2 \\
\hline & Need handrail on stairs & 3 \\
\hline & $\begin{array}{l}\text { Able to walk w/o walking aid, but } \\
\text { inadequate }\end{array}$ & 4 \\
\hline & Normal function & 5 \\
\hline \multirow[t]{4}{*}{ Sensory } & Upper extremity/lower extremity/trunk & \\
\hline & Apparent sensory loss & 1 \\
\hline & Minimal sensory loss & 2 \\
\hline & Normal function & 3 \\
\hline \multirow[t]{4}{*}{ Bladder function } & Urinary retention & 1 \\
\hline & Severe dysfunction & 2 \\
\hline & Mild dysfunction & 3 \\
\hline & Normal function & 4 \\
\hline
\end{tabular}

* Total score 0-17.

the chi-square or Fisher exact test whenever appropriate, and continuous variables using independent-sample t-tests or Wilcoxon rank-sum tests if not normally distributed. The paired t-test was used to compare the preoperative values to the postoperative values of the mJOA scale and MS. Statistical significance was defined as $\mathrm{p}<0.05$. Results are reported as mean change with $95 \%$ confidence intervals (CIs). Spearman's correlation coefficient and $\mathrm{p}$ value were used to test the strength of the correlation between the mJOA scale and MS. All statistical analyses were performed using SPSS (version 20.0, IBM).

\section{Results}

In this prospective cohort study, 47 patients met the strict inclusion criteria and were enrolled. Thirty-six patients completed a 1-year postoperative follow-up period (Table 2). Eleven patients were lost to follow-up at 1 year. Long-term duration of myelopathic symptoms ( $>3$ years) was reported in 24 patients $(66.7 \%)$. Cervical laminoplasty was the most commonly used procedure in our study (30 patients, $83.3 \%)$. The mean age ( \pm SD) of the patients was $63.0 \pm 13.2$ years. There were 28 males $(77.8 \%)$ and 8 females $(22.2 \%)$. Thirty-two patients $(88.9 \%)$ were retired at the time of presentation. The MRI stenosis severity based on radiological evaluation was as follows: mild in 0 patients $(0 \%)$, moderate in 4 patients $(11.1 \%)$, and severe in 32 patients $(88.9 \%$; Table 3$)$. A statistically significant change postoperatively at 1 year compared with preoperatively was noted with the following myelopathic signs: reflexes, Babinski sign, and proprioception signs $(\mathrm{p}=<$ $0.001, p=0.008$, and $\mathrm{p}=0.015$, respectively). There was an improvement in Hoffman's sign postoperatively, although it did not reach a statistical level of significance ( $p$
$=0.091)$. No statistically significant improvement with the clonus sign was noted ( $\mathrm{p}=0.368$; Tables 4 and 5).

We also noticed a statistically significant improvement in the degree of myelopathy based on the postoperative mJOA scale score at 1 year compared with the preoperative mJOA scale score. The mean postoperative mJOA scale score at 1 year improved by $2.8 \pm 1.6$ points $(95 \%$ CI 2.2-3.3 points) compared with the mean preoperative mJOA score $(\mathrm{p}<0.001)$, and the mean percentage change in mJOA scale score was $29.8 \%$ and in MS score was $38.7 \%$, indicating a significant degree of improvement in myelopathy based on this functional outcome scale following cervical surgical decompression. Similarly, our MS score showed a statistically significant degree of improvement following surgery at 1 year, with a mean difference of $-1.9 \pm 1.7$ points $(95 \% \mathrm{CI}-2.4$ to -1.3$)$ at 1 year ( $\mathrm{p}<0.001)$, indicating as well a statistically significant improvement. There was a small and nonsignificant inverse correlation between preoperative mJOA scale and MS scores (Spearman's correlation coefficient -0.202, p $=0.238$ ), and a similar observation was also noted for the correlation between postoperative mJOA scale and MS scores $(-0.361, \mathrm{p}=0.031$; Tables $6-8)$.

In $29(80.6 \%)$ of the 36 patients, there was an improvement in the scores of both scales at 1 year postoperatively. Five $(13.9 \%)$ of 36 patients improved on the mJOA scale and did not change on the MS. Two (5.6\%) of 36 patients demonstrated no change on either scale. Of note, 2 patients experienced recurrence of severe myelopathy that required reoperation. One was due to a motor vehicle accident 8 months after surgery, and the other patient experienced a clinical neurological decline. The reoperations were excluded from the statistical analysis.

\section{Discussion}

One of the challenges in evaluating success following cervical decompression surgery for patients with CSM has been the reliance on outcome measures and scales that are largely dependent on the surgeon or patient's subjective impression of outcome. ${ }^{6}$ Several scales used to assess patients with myelopathy are discussed in the literature. These scales rely on subjective recording of patient's symptoms and overall functionality. CSM is a condition that relies on objective myelopathic signs for diagnosis; however, to date, no known study has examined the correlation between functional outcome and myelopathic signs following cervical decompression surgery. ${ }^{6}$ Our current study was essentially designed to address this question.

Given that CSM is largely defined based on the fundamental signs of myelopathy, we attempted in this study to find out how myelopathic signs change over time following surgery and what is the relationship of these changes to functional outcome. Nurick et al. classified myelopathy into 6 grades (Grades $0-5$ ), but this grading system only assesses disabilities focused at the lower extremities. We contend that the mJOA scoring system is a more thorough system for assessing the degree of cervical myelopathy, because it includes evaluation of the upper and lower limbs, as well as sensory and bladder function. ${ }^{17}$

In our study, the degree of CSM was evaluated according to the mJOA scale prior to surgery and at the final 
TABLE 2. Baseline patient characteristics

\begin{tabular}{|c|c|c|c|c|c|c|}
\hline Case No. & $\begin{array}{l}\text { Age (yrs), } \\
\text { Sex }\end{array}$ & $\begin{array}{l}\text { Duration of Myelopathy at } \\
\text { Presentation (yrs) }\end{array}$ & $\begin{array}{l}\text { Preop mJOA } \\
\text { Score }\end{array}$ & $\begin{array}{c}\text { Postop mJOA Score } \\
\text { at } 1 \mathrm{Yr}\end{array}$ & Preop MS & $\begin{array}{c}\text { Postop MS at } \\
1 \mathrm{Yr}\end{array}$ \\
\hline 1 & $76, \mathrm{M}$ & $>3$ & 16 & 16 & 6 & 6 \\
\hline 2 & $66, M$ & $>3$ & 13 & 14 & 6 & 6 \\
\hline 3 & $56, \mathrm{M}$ & $>3$ & 10 & 12 & 6 & 5 \\
\hline 4 & $75, \mathrm{M}$ & $<1$ & 9 & 14 & 4 & 4 \\
\hline 5 & $42, \mathrm{M}$ & $<1$ & 9 & 12 & 5 & 5 \\
\hline 6 & $64, F$ & $1-3$ & 11 & 15 & 5 & 2 \\
\hline 7 & $77, \mathrm{M}$ & $>3$ & 5 & 8 & 10 & 8 \\
\hline 8 & $77, \mathrm{M}$ & $>3$ & 8 & 12 & 4 & 4 \\
\hline 9 & $43, M$ & $>3$ & 11 & 15 & 7 & 6 \\
\hline 10 & $62, \mathrm{M}$ & $>3$ & 9 & 13 & 4 & 0 \\
\hline 11 & $52, \mathrm{M}$ & $<1$ & 12 & 14 & 6 & 5 \\
\hline 12 & $73, \mathrm{M}$ & $>3$ & 12 & 13 & 6 & 4 \\
\hline 13 & $80, F$ & $>3$ & 7 & 13 & 6 & 2 \\
\hline 14 & $65, M$ & $>3$ & 10 & 13 & 5 & 4 \\
\hline 15 & $45, M$ & $1-3$ & 12 & 16 & 5 & 2 \\
\hline 16 & $67, \mathrm{M}$ & $>3$ & 9 & 13 & 10 & 5 \\
\hline 17 & $48, M$ & $1-3$ & 12 & 15 & 10 & 5 \\
\hline 18 & $60, M$ & $>3$ & 14 & 15 & 6 & 2 \\
\hline 19 & $70, M$ & $>3$ & 12 & 14 & 2 & 0 \\
\hline 20 & $77, \mathrm{M}$ & $>3$ & 12 & 15 & 4 & 0 \\
\hline 21 & $42, \mathrm{M}$ & $1-3$ & 12 & 14 & 3 & 2 \\
\hline 22 & $73, \mathrm{M}$ & $<1$ & 12 & 15 & 4 & 0 \\
\hline 23 & $50, M$ & $1-3$ & 13 & 16 & 4 & 2 \\
\hline 24 & $78, \mathrm{M}$ & $>3$ & 9 & 11 & 5 & 5 \\
\hline 25 & $52, \mathrm{M}$ & $1-3$ & 10 & 11 & 7 & 6 \\
\hline 26 & $65, M$ & $<1$ & 15 & 15 & 1 & 4 \\
\hline 27 & $54, \mathrm{M}$ & $>3$ & 8 & 15 & 4 & 2 \\
\hline 28 & $39, \mathrm{M}$ & $>3$ & 15 & 16 & 4 & 2 \\
\hline 29 & $52, F$ & $>3$ & 9 & 12 & 3 & 2 \\
\hline 30 & $75, \mathrm{M}$ & $>3$ & 10 & 14 & 6 & 3 \\
\hline 31 & $70, \mathrm{~F}$ & $>3$ & 10 & 12 & 2 & 0 \\
\hline 32 & $73, \mathrm{~F}$ & $>3$ & 12 & 16 & 3 & 0 \\
\hline 33 & $47, \mathrm{~F}$ & $1-3$ & 14 & 16 & 4 & 3 \\
\hline 34 & $81, F$ & $>3$ & 13 & 14 & 6 & 4 \\
\hline 35 & $59, \mathrm{~F}$ & $>3$ & 13 & 15 & 4 & 2 \\
\hline 36 & $83, \mathrm{M}$ & $>3$ & 5 & 9 & 7 & 5 \\
\hline
\end{tabular}

follow-up assessment. The mJOA scale score determines the clinical and functional status of patients by evaluating upper limb (4 points), lower limb (4 points), sensory (6 points), and urinary bladder function (3 points). ${ }^{11}$ However, the mJOA scale score has been shown to have a variable degree of fluctuation of at least 1 point with interobserver and intraobserver rating differences. ${ }^{17}$ Also, the mJOA scale relies heavily on a patient's subjective feedback and does not involve objective examination of myelopathic signs.

The diagnosis of myelopathy is based on the presence of myelopathic signs in conjunction with supportive imaging findings. There was no indication for postoperative MRI, as the practice in our center is not routinely performed except when there is neurological deterioration postoperatively. Two of our patients experienced a degree of worsening postoperatively ( 1 of them due to a motor vehicle accident), and both obtained postoperative MRI as part of the evaluation workup. Because of this, we have attempted to develop an MS that directly integrates the basic signs of myelopathy. This differentiates our scale from previously used scales. The future question to answer is whether a myelopathic scale based on myelopathic signs can contribute to our clinical assessment and management of patients. If our scale can be correlated with improvement in functional outcome as assessed by the mJOA scale, our scale 
TABLE 3. Patient demographics

\begin{tabular}{cc}
\hline Variable & Value (\%) \\
\hline No. of patients & 36 \\
\hline Mean age \pm SD (yrs) & $63.0 \pm 13.2$ \\
\hline Age group (yrs) & $8(22.2)$ \\
\hline $18-50$ & $20(55.6)$ \\
\hline $51-75$ & $8(22.2)$ \\
\hline$>75$ & \\
\hline Sex & $28(77.8)$ \\
\hline Male & $8(22.2)$ \\
\hline Female & \\
\hline MRI severity & $0(0)$ \\
\hline Mild & $4(11.1)$ \\
\hline Moderate & $32(88.9)$ \\
\hline Severe
\end{tabular}

may be used as a tool to predict patient outcome following cervical decompression surgery.

Our study showed a statistically significant improvement in the degree of myelopathy as shown in our results with improvement in both myelopathic scales. These results may prompt health care practitioners to look for, or even expect, a lessening or resolution of myelopathic signs when judging the success of treatment.

Approximately $95 \%$ of our patients had preoperative gait abnormalities, $85 \%$ had severe cervical spinal cord compression, and about $65 \%$ had retained their motor strength of at least 4/5 in all muscle groups tested (based on the Medical Research Council scale).

Sphincter abnormalities were found in $20 \%$ of patients. One patient (Case 26) of our 36 surgically treated patients demonstrated postoperative worsening of MS scores at 1 year. This patient's MS score increased by 3 points and required a second surgery after 1 year. Interestingly, this patient's mJOA scale score was the same pre- and postoperatively at 1 year. Five patients had no change in MS score (13.9\%), which interestingly coincided with improvement in the mJOA scale scores, while there was an agreement

TABLE 4. Frequency of preoperative and postoperative myelopathic signs

\begin{tabular}{lccc}
\hline \multicolumn{1}{c}{ Signs } & Negative (\%) & Unilateral (\%) & Bilateral (\%) \\
\hline Preop & & & \\
\hline Reflexes & $1(2.8)$ & $5(13.9)$ & $30(83.3)$ \\
\hline Proprioception & $24(66.7)$ & $8(22.2)$ & $4(11.1)$ \\
\hline Clonus & $31(86.1)$ & $2(5.6)$ & $3(8.3)$ \\
\hline Hoffman & $8(22.2)$ & $6(16.7)$ & $22(61.1)$ \\
\hline Babinski & $10(27.8)$ & $7(19.4)$ & $19(52.8)$ \\
\hline Postop (1 yr) & & & \\
\hline Reflexes & $12(33.3)$ & $9(25.0)$ & $15(41.7)$ \\
\hline Proprioception & $34(94.4)$ & $1(2.8)$ & $1(2.8)$ \\
\hline Clonus & $33(91.7)$ & $2(5.6)$ & $1(2.8)$ \\
\hline Hoffman & $14(38.9)$ & $7(19.4)$ & $15(41.7)$ \\
\hline Babinski & $20(55.6)$ & $7(19.4)$ & $9(25.0)$ \\
\hline
\end{tabular}

TABLE 5. Changes in postoperative myelopathic signs 1 year postoperatively

\begin{tabular}{cclll}
\hline & \multicolumn{3}{c}{ 1-Yr Postop (\%) } & \\
\cline { 2 - 4 } Preop Signs & Negative & Unilateral & Bilateral & p Value \\
\hline Reflexes & & & & $<0.001$ \\
\hline Negative & $1(2.8)$ & 0 & 0 & \\
\hline Unilateral & $3(8.3)$ & $2(5.6)$ & 0 & \\
\hline Bilateral & $8(22.2)$ & $7(19.4)$ & $15(41.7)$ & \\
\hline Proprioception & & & & 0.015 \\
\hline Negative & $23(63.9)$ & $1(2.8)$ & 0 & \\
\hline Unilateral & $8(22.2)$ & 0 & 0 & \\
\hline Bilateral & $3(8.3)$ & 0 & $1(2.8)$ & \\
\hline Clonus & & & & \\
\hline Negative & $30(83.3)$ & $1(2.8)$ & 0 & \\
\hline Unilateral & $1(2.8)$ & $1(2.8)$ & 0 & \\
\hline Bilateral & $2(5.6)$ & 0 & $1(2.8)$ & \\
\hline Hoffman & & & & \\
\hline Negative & $7(19.4)$ & 0 & $1(2.8)$ & \\
\hline Unilateral & $2(5.6)$ & $3(8.3)$ & $1(2.8)$ & \\
\hline Bilateral & $5(13.9)$ & $4(11.1)$ & $13(36.1)$ & \\
\hline Babinski & & & & 0.0081 \\
\hline Negative & $10(27.8)$ & 0 & 0 & \\
\hline Unilateral & $3(8.3)$ & $3(8.3)$ & $1(2.8)$ & \\
\hline Bilateral & $7(19.4)$ & $4(11.1)$ & $8(22.2)$ & \\
\hline & & & & \\
\hline
\end{tabular}

in improvement in both myelopathic signs and functional outcome following surgical decompression between the 2 scales of 30 patients $(83.3 \%)$ with a strength of agreement (kappa) of 0.160 (Table 9).

The overall improvement in MS scores was statistically significant $(\mathrm{p}<0.001)$. Furthermore, when we broke down the MS into its basic components, we found that the following signs had statistically significant improvement: reflexes $(\mathrm{p}<0.001)$, proprioception $(\mathrm{p}=0.015)$, and Babin-

TABLE 6. Pre- and postoperative mJOA and MS scores

\begin{tabular}{|c|c|c|}
\hline Variable & Mean \pm SD & $95 \% \mathrm{Cl}$ \\
\hline \multicolumn{3}{|l|}{ Preop } \\
\hline mJOA & $10.9 \pm 2.6$ & $5-16$ \\
\hline MS & $5.1 \pm 2.1$ & $1-10$ \\
\hline \multicolumn{3}{|l|}{ 1-Yr Postop } \\
\hline mJOA & $13.7 \pm 2.0$ & $8-16$ \\
\hline MS & $3.3 \pm 2.1$ & $0-8$ \\
\hline \multicolumn{3}{|c|}{ Change from preop (mean difference) } \\
\hline mJOA & $2.8 \pm 1.6$ & $2.2-3.3$ \\
\hline MS & $-1.9 \pm 1.7$ & -2.4 to -1.3 \\
\hline \multicolumn{3}{|l|}{ Percentage change ${ }^{*}$} \\
\hline mJOA & $29.8 \pm 22.4$ & $(0-87.5)$ \\
\hline MS & $38.7 \pm 40.5$ & $(-100 \dagger$ to 100$)$ \\
\hline
\end{tabular}


TABLE 7. Comparison of pre- and postoperative mean mJOA and MS scores*

\begin{tabular}{lcccc}
\hline Score Comparison & Mean Difference & SD & $95 \% \mathrm{Cl}$ & $\mathrm{p}$ Value \\
\hline Postop \& preop mJOA & 2.8 & 1.6 & $2.3-3.3$ & $<0.001$ \\
\hline Postop \& preop MS & -1.9 & 1.7 & -2.4 to -1.3 & $<0.001$ \\
\hline
\end{tabular}

* Statistical analysis was performed using the paired-samples t-test.

ski's sign $(p=0.008)$. A lesser degree of improvement was seen with Hoffman's sign ( $p=0.091)$, and no improvement occurred with clonus $(\mathrm{p}=0.368)$. The improvement in these 3 myelopathic signs corresponded to the improvement in mJOA scale scores, even though the correlation between the 2 scales was not robust.

In our study, when we tested the strength of correlation between our MS and the mJOA scale, it was noted that there is a weak degree of inverse correlation between the 2 scales, even though both scales showed statistically significant improvement postoperatively at 1 year. This appears to show that functional improvement as demonstrated by an increased score on the mJOA scale depends to some extent on patients having fewer myelopathic signs as shown by the decreased score on our MS. The degree to which one depends on the other appears to be mildly correlated. Further studies with larger numbers of patients will need to be conducted to determine whether functional improvement as assessed by scales such as the mJOA would require a lessening of myelopathic signs. However, it is possible that patients can improve functionally following cervical decompressive surgery but nonetheless be left with residual signs of myelopathy.

Other researchers have compared myelopathy scales with other neurological tests. Schön ${ }^{15}$ compared sensory evoked potentials with the lower European Myelopathy Scale (EMS). Lyu et al. ${ }^{10}$ studied the degree of correlation between the nonmodified version of the JOA scoring system with that of sensory evoked potentials. Both of these studies also found a weak degree of correlation when they tested these modalities against each other, which is consistent with our finding of the weak correlation between the 2 scales we tested.
TABLE 9. Agreement between mJOA and MS*

\begin{tabular}{|c|c|c|c|c|}
\hline \multirow[b]{2}{*}{ MS Outcome } & \multicolumn{3}{|c|}{ mJOA Score } & \multirow{2}{*}{$\begin{array}{l}\text { Measure of } \\
\text { Agreement } \\
\text { (kappa) }\end{array}$} \\
\hline & Worsened & $\begin{array}{c}\text { No } \\
\text { Change }\end{array}$ & Improved & \\
\hline MS & & & & 0.160 \\
\hline Worsened & 0 & $1(2.7 \%)$ & 0 & \\
\hline No change & 0 & 0 & $5(13.9 \%)$ & \\
\hline Improved & 0 & 0 & $30(83.3 \%)$ & \\
\hline
\end{tabular}

* Worsened, improved, or no change from preoperative score. Percentages based on $n=36$.

An interesting finding in our study was noted upon examining patients who completed a 2-year postoperative follow-up interval (12 patients). All of these patients continued to show improvement in mJOA scores by at least 1 point at the 2-year follow-up compared with 1 year follow-up. Of these 12 patients, only 3 improved by at least 1 point on the MS scores, and 9 patients had no further improvement in the scores at 2 years compared with scores at 1 year. This interesting observation leads one to question whether functional outcome can continue to improve after 1 year following surgery even though myelopathic sign resolution will level off after 1 year.

\section{Limitations of the Study}

This study has several limitations. It has a relatively small number of patients and was conducted at a single center. However, we are presenting unique findings of myelopathy not previously reported in the literature.

\section{Conclusions}

Our newly devised MS showed a statistically significant improvement at postoperative Year 1, which is consistent with the improvement noted with the mJOA scale score. This study could form the basis for further testing of myelopathy pre- and postoperatively following cervical decompression surgery. Further studies should be conducted in an effort to better understand the relationship between

TABLE 8. Correlation between pre- and postoperative mJOA and MS scores using Spearman correlation coefficient

\begin{tabular}{|c|c|c|c|c|}
\hline Assessment & Preop mJOA Score & Postop mJOA Score & Preop MS & Postop MS \\
\hline \multicolumn{5}{|l|}{ Preop mJOA } \\
\hline Correlation coefficient & 1 & 0.745 & -0.202 & -0.147 \\
\hline$p$ value & - & $<0.001$ & 0.238 & 0.392 \\
\hline \multicolumn{5}{|l|}{ Postop mJOA } \\
\hline Correlation coefficient & 0.745 & 1 & -0.269 & -0.361 \\
\hline$p$ value & $<0.001$ & - & 0.113 & 0.031 \\
\hline \multicolumn{5}{|l|}{ Preop MS } \\
\hline Correlation coefficient & -0.202 & -0.269 & 1 & 0.733 \\
\hline$p$ value & 0.238 & 0.113 & - & $<0.001$ \\
\hline \multicolumn{5}{|l|}{ Postop MS } \\
\hline Correlation coefficient & -0.147 & -0.361 & 0.733 & 1 \\
\hline$p$ value & 0.392 & 0.031 & $<0.001$ & - \\
\hline
\end{tabular}


improvements in myelopathic signs and functional outcome. Further studies and evaluation of our proposed MS will allow us to possibly validate the scale through more vigorous testing, including interobserver reliability.

\section{Acknowledgments}

We thank administrative assistant Mrs. Christine Vandervlist at Hamilton Health Sciences for her comprehensive assistance in data management. We would also like to thank Ms. Chelsea Battell and Dyda Dao from the Department of Epidemiology for their contribution to the statistical analysis.

\section{References}

1. Baron EM, Young WF: Cervical spondylotic myelopathy: a brief review of its pathophysiology, clinical course, and diagnosis. Neurosurgery 60 (1 Supp1 1):S35-S41, 2007

2. Chiles BW III, Leonard MA, Choudhri HF, Cooper PR: Cervical spondylotic myelopathy: patterns of neurological deficit and recovery after anterior cervical decompression. Neurosurgery 44:762-770, 1999

3. Cusick JF: Pathophysiology and treatment of cervical spondylotic myelopathy. Clin Neurosurg 37:661-681, 1991

4. Fehlings MG, Skaf G: A review of the pathophysiology of cervical spondylotic myelopathy with insights for potential novel mechanisms drawn from traumatic spinal cord injury. Spine (Phila Pa 1976) 23:2730-2737, 1998

5. Herdmann J, Linzbach M, Krzan M, Dvorak J, Bock WJ: The European Myelopathy Score, in Bauer BL, Brock M, Klinger M (eds): Advances in Neurosurgery. Berlin: Springer, 1994, pp 266-268

6. Holly LT, Matz PG, Anderson PA, Groff MW, Heary RF, Kaiser MG, et al: Functional outcomes assessment for cervical degenerative disease. J Neurosurg Spine 11:238-244, 2009

7. Hukuda S, Mochizuki T, Ogata M, Shichikawa K, Shimomura Y: Operations for cervical spondylotic myelopathy. A comparison of the results of anterior and posterior procedures. J Bone Joint Surg Br 67:609-615, 1985

8. Keller A, von Ammon K, Klaiber R, Waespe W: [Spondylogenic cervical myelopathy: conservative and surgical therapy.] Schweiz Med Wochenschr 123:1682-1691, 1993 (Ger)

9. Lebl DR, Hughes A, Cammisa FP Jr, O'Leary PF: Cervical spondylotic myelopathy: pathophysiology, clinical presentation, and treatment. HSS J 7:170-178, 2011

10. Lyu RK, Tang LM, Chen CJ, Chen CM, Chang HS, Wu YR: The use of evoked potentials for clinical correlation and surgical outcome in cervical spondylotic myelopathy with intramedullary high signal intensity on MRI. J Neurol Neurosurg Psychiatry 75:256-261, 2004

11. Morio Y, Teshima R, Nagashima H, Nawata K, Yamasaki D, Nanjo Y: Correlation between operative outcomes of cervical compression myelopathy and mri of the spinal cord. Spine (Phila Pa 1976) 26:1238-1245, 2001

12. Nurick $\mathrm{S}$ : The pathogenesis of the spinal cord disorder associated with cervical spondylosis. Brain 95:87-100, 1972

13. Prolo DJ, Oklund SA, Butcher M: Toward uniformity in evaluating results of lumbar spine operations. A paradigm applied to posterior lumbar interbody fusions. Spine (Phila Pa 1976) 11:601-606, 1986

14. Sayana MK, Jamil H, Poynton A: Cervical laminoplasty for multilevel cervical myelopathy. Adv Orthop 2011:241729, 2011

15. Schön H: Stellenwert der somatosensibel evozierten Potentiale in der prä- und postoperativen Beurteilung der zervikalen spondylophytär bedingten Myelopathie [dissertation]. Leipzig: Universität Leipzig, 2000.

16. Seng C, Tow BP, Siddiqui MA, Srivastava A, Wang L, Yew AK, et al: Surgically treated cervical myelopathy: a functional outcome comparison study between multilevel anterior cervical decompression fusion with instrumentation and posterior laminoplasty. Spine J 13:723-731, 2013

17. Sumi M, Miyamoto H, Suzuki T, Kaneyama S, Kanatani T, Uno K: Prospective cohort study of mild cervical spondylotic myelopathy without surgical treatment. J Neurosurg Spine 16:8-14, 2012

\section{Disclosures}

The authors report no conflict of interest concerning the materials or methods used in this study or the findings specified in this paper.

\section{Author Contributions}

Conception and design: Kachur, El-Zuway. Acquisition of data: Kachur, El-Zuway. Analysis and interpretation of data: all authors. Drafting the article: Kachur, El-Zuway. Critically revising the article: all authors. Reviewed submitted version of manuscript: all authors. Approved the final version of the manuscript on behalf of all authors: Kachur. Statistical analysis: Farrokhyar. Study supervision: Kachur, El-Zuway.

\section{Correspondence}

Edward Kachur, McMaster Clinic Wing, 7th Fl., Rm. 715, Hamilton Health Sciences, 237 Barton St. E, Hamilton, ON L8L 2X2, Canada.email: edkachur16@gmail.com. 